\title{
PENGARUH NPWP DAN SANKSI PERPAJAKAN TERHADAP \\ KEPATUHAN WAJIB PAJAK \\ (Studi Kasus Civitas Akademika Universitas Islam Syekh-Yusuf Tangerang)
}

\author{
Nela Dharmayanti \\ Siti Aisyah Humayroh
}

Fakultas Ekonomi, Program Study Akuntansi.

Universitas Islam Syekh Yusuf Tangerang

\begin{abstract}
ABSTRACK
Penelitian ini bertujuan untuk menguji pengaruh NPWP dan sanksi perpajakan terhadap kepatuhan wajib pajak. Populasi yang digunakan pada penelitian ini yaitu dosen, mahasiswa/i dan karyawan Universitas Islam SyekhYusuf Tangerang yang berjumlah 4.353 dan untuk sampelnya berjumlah 98 responden wajib pajak di Universitas Islam Syekh-Yusuf Tangerang dengan menggunakan rumus Slovin. Hasil dalam penelitian ini dikumpulkan melalui kuesioner yang di proses dan di analisis dengan menggunakan analisa regresi berganda. Metode yang digunakan dalam penelitian ini adalah metode kuantitatif. Uji kualitas data yang digunakan dalam penelitian ini adalah uji validitas pearson correlation dan uji reliabilitas menggunakan Cronbach Alpha. Untuk uji hipotesis dalam penelitian ini, peneliti menggunakan uji $R^{2}$ yang sudah disesuaikan, uji $F$ dan uji t. Hasil dalam penelitian ini membuktikan bahwa terdapat hubungan sangat kuat antara NPWP terhadap kepetuhan wajib pajak dengan nilai korelasi 0,806. Kontribusi sanksi perpajakan terhadap kepatuhan wajib pajak sebesar $27,1 \%$ sisanya dipengaruhi faktor lain yang belum diteli dikarenakan keterbatasan waktu dan biaya, serta dan $t_{\text {hitung }}>t_{\text {tabel }}$ (5,971 > 1,984), maka Ho2 ditolak dan Ha2 diterima, yang berarti terdapat pengaruh yang positif dan signifikan antara NPWP dan sanksi perpajakan kepatuhan wajib pajak. Sedangkan secara simultan terdapat hubungan yang sangat kuat antara NPWP dan sanksi perpajakan terhadap kepatuhan wajib pajak dengan nilai korelasi 0,820.
\end{abstract}

Kata Kunci : NPWP, Sanksi Perpajakan, Kepatuhan Wajib Pajak. 


\section{PENDAHULUAN}

Salah satu tujuan pemerintah Negara Indonesia yang tertuang dalam pembukaan Undang-Undang Dasar 1945 adalah untuk memajukan kesejahteraan umum. Hal tersebut dapat diwujudkan dengan menjalankan pemerintahan yang baik dan melaksanakan pembangunan di segala bidang, tentunya dengan didukung oleh sumber pembiayaan yang memadai. Salah satu sumber pembiayaan negara adalah pajak. Pajak merupakan pemberi kontribusi terbesar dalam penerimaan negara, mempunyai dampak yang sangat besar bagi kelangsungan Negara Republik Indonesia. Walaupun masih ada sektor-sektor lain yang juga memberikan kontribusinya dalam penerimaan negara, pajak tetap menjadi yang paling dominan.

Berdasar Undang-Undang Dasar 1945 (UUD 45) pasal 23-A dinyatakan bahwa "Pajak dan pungutan lain yang bersifat memaksa untuk keperluan negara diatur dengan Undang-Undang".

Menurut pasal 1 Undang-Undang tentang Ketentuan Umum dan Tata Cara Perpajakan (KUP) No 28 tahun 2007 berbunyi:

"Pajak adalah kontribusi kepada negara yang terutang oleh orang pribadi atau badan yang bersifat memaksa berdasarkan undang-undang, dengan tidak mendapatkan imbalan secara langsung dan digunakan untuk keperluan negara bagi sebesar-besarnya kemakmuran rakyat".

Kontribusi pajak dalam Anggaran Pendapatan dan Belanja Negara (APBN) setiap tahun semakin meningkat. Hal ini menunjukan bahwa peranan pajak semakin besar dalam APBN. Oleh karena itu, Direktorat Jendral Pajak terus berupaya meningkatkan penerimaan pajak. Dalam meningkatkan penerimaan pajak ada beberapa strategi yang dilakukan oleh Direktorat Jendral pajak, diantaranya adalah penyempurnaan sistem administrasi perpajakan, kegiatan penagihan, kegiatan ekstensifikasi,

Kepatuhan wajib pajak dapat pula ditingkatkan melalui pengenaan sanksi perpajakan. Undang-undang dan peraturan telah mengatur 
bagaimana pelaksanaan ketentuan umum dan tata cara perpajakan, termasuk sanksi yang akan dikenakan apabila wajib pajak tidak memenuhi kewajiban perpajakannya. Pengenaan sanksi bertujuan untuk mencegah ketidakpatuhan wajib pajak. Itulah sebabnya, penting bagi wajib pajak memahami sanksi-sanksi perpajakan sehingga mengetahui konsekuensi hukum dari apa yang dilakukan ataupun tidak dilakukan.Menurut Undang-Undang Nomor 28 Tahun 2007, tugas Direktorat Jendral Pajak adalah berperan aktif dalam melaksanakan pengendalian administrasi pemungutan pajak yang meliputi tugas-tugas pembinaan, penelitian, pengawasan, dan penerapan sanksi administrasi. Ketegasan Direktorat Jendral Pajak dalam menerapkan sanksi kepada wajib pajak yang tidak memenuhi kewajibannya sangat diperlukan sehingga terbentuk perilaku kepatuhan wajib pajak. Walaupun sudah diatur dalam peraturan Undangundang yang jelas, masih banyak warga negara belum sadar untuk memenuhi Hak dan Kewajiban Perpajakannya yaitu kewajiban untuk memiliki Nomor Pokok Wajib Pajak (NPWP) dan membayar, menghitung, memperhitungkan dan melaporkan pajaknya.

\section{Pengembangan Hipotesis}

\section{Pengaruh NPWP terhadap Kepatuhan Wajib Pajak}

Nomor Pokok Wajib Pajak (NPWP) merupakan suatu sarana dalam administrasi perpajakan yang dipergunakan sebagai tanda pengenal diri atau identitas Wajib Pajak.

Berdasarkan penelitan yang dilakukan oleh Masruroh (2013) mengatakan bahwa kemanfaatan NPWP akan mempengaruhi penilaian masing-masing wajib pajak untuk berperilaku patuh dalam melaksanakan kewajiban perpajakan. Manfaat yang dapat dirasakan dan selaras dengan kepentingan wajib pajak akan memotivasi wajib pajak untuk memilih berperilaku patuh dalam melaksanakan kewajiban perpajakan. Berdasarkan penjabaran di atas, maka diajukan hipotesis sebagai berikut:

H1: Nomor Pokok Wajib Pajak (NPWP) berpengaruh positif terhadap kepatuhan wajib pajak 
Pengaruh Sanksi Perpajakan terhadap Kepatuhan Wajib Pajak

Sanksi perpajakan merupakan penyebab eksternal yang mempengaruhi persepsi seorang wajib pajak dalam membentuk penilaian mengenai perilaku kepatuhan wajib pajak dalam melaksanakan kewajiban perpajakan.

Berdasarkan penelitan yang dilakukan oleh Triyana (2013) mengatakan sanksi Pajak merupakan faktor yang memberikan pengaruh terbesar terhadap kepatuhan wajib pajak dan fakta ini berhubungan dengan sanksi yang tidak ringan yang dapat diterima oleh wajib pajak ketika terdapat suatu keterlambatan atau bahkan pelanggaran administratif atau pidana terhadap penetapan pajak atas wajib pajak tersebut. Berdasarkan penjabaran di atas, maka diajukan hkipotesis sebagai berikut:

H2: Sanksi perpajakan berpengaruh positif terhadap kepatuhan wajib pajak Pengaruh NPWP dan Sanksi Perpajakan terhadap Kepatuhan Wajib Pajak

Masruroh (2013) mengatakan bahwa kemanfaatan NPWP akan mempengaruhi penilaian masing-masing wajib pajak untuk berperilaku patuh dalam melaksanakan kewajiban perpajakan. Triyana (2013) mengatakan sanksi Pajak merupakan faktor yang memberikan pengaruh terbesar terhadap kepatuhan wajib pajak dan fakta ini berhubungan dengan sanksi yang tidak ringan yang dapat diterima oleh wajib pajak ketika terdapat suatu keterlambatan atau bahkan pelanggaran administratif atau pidana terhadap penetapan pajak atas wajib pajak tersebut.

H3: Nomor pokok wajib pajak (NPWP) dan sanksi perpajakan berpengaruh poisitif terhadap kepatuhan wajib pajak

\section{METODE PENELITIAN}

Variabel Penelitian

Penelitian ini terdiri dari tiga variabel, yaitu dua variabel independen dan satu variabel dependen. Variabel independen dalam 
penelitian ini adalah NPWP (X1), dan sanksi perpajakan (X2). Variabel dependen dalam penelitian ini adalah kepatuhan wajib pajak (Y). Pengukuran variabel-variabel independen menggukan teknik pengukurang skala likert 5 poin.

\section{Populasi dan Sampel}

Populasi dalam penelitian ini adalah seluruh dosen, mahasiswa/i, dan karyawan Universitas Islam Syekh-Yusuf Tangerang yang sudah bekerja dan memiliki NPWP. Berdasarkan data dari Universitas Islam Syekh-Yusuf Tangerang tahun 2017 jumlah Civitas Akademika Universitas Islam Syekh-Yusuf sebanyak 4.353.

\section{Objek Penelitian}

Objek dalam penelitian ini yaitu wajib pajak yang berada di wilayah Universitas Islam Syekh-Yusuf Tangerang. Jumlah wajib pajak di Universitas Islam Syekh-Yusuf Tangerang sebanya 4.353 wajib pajak. Data tersebut diperoleh dengan menyebarkan kuesioner kepada wajib pajak yang ada diwilayah Universitas Islam Syekh-Yusuf Tangerang sebanyak 98 responden. Penyebaran kuesioner dilakukan dengan cara mendatangi wajib pajak yang ada di wilayah Universitas Islam SyekhYusuf Tangerang.

\section{HASIL PENELITIAN}

\section{Uji Validitas}

Pengujian ini dilakukan dengan menggunakan corrected item total correlation yanitu dngena cara mengkorelasikan skor tiap item dengan skor totalnya, item pernyataan valid jika $r$ hitung lebih besar dari r standar yaitu 0,50 .

\section{Tabel 2}

\section{Hasil Uji Validitas NPWP (Nomor Pokok Wajib Pajak)}

\begin{tabular}{|c|c|c|c|}
\hline Pernyataan & R hitung & R standar & Keterangan \\
\hline P1 & 0,573 & 0,30 & Valid \\
\hline P2 & 0,736 & 0,30 & Valid \\
\hline
\end{tabular}




\begin{tabular}{|c|c|c|c|}
\hline P3 & 0,541 & 0,30 & Valid \\
\hline P4 & 0,746 & 0,30 & Valid \\
\hline P5 & 0,661 & 0,30 & Valid \\
\hline
\end{tabular}

Sumber: data Primer yang diolah, 2017

Berdasarkan tabel 2 menujukan bahwa seluruh pertanyaan tersebut valid, karena masing-masing memiliki nilai $\mathrm{r}$ hitung lebih dari 0,30 ( $r$ hitung $>r$ standar).

Pengujian selanjutnya adalah uji validitas untuk variabel Sanksi Perpajakan dimana jumlah pernyataan sebanyak 5 butir. Hasil pengujian validitas untuk variabel Sanksi Perpajakan dapat dilihat pada tabel 3

Tabel 3

Hasil Uji Validitas Sanksi Perpajakan

\begin{tabular}{|c|c|c|c|}
\hline Pernyataan & R hitung & R standar & Keterangan \\
\hline P6 & 0,423 & 0,30 & Valid \\
\hline P7 & 0,698 & 0,30 & Valid \\
\hline P8 & 0,645 & 0,30 & Vadil \\
\hline P9 & 0,768 & 0,30 & Valid \\
\hline P10 & 0,739 & 0,30 & Valid \\
\hline
\end{tabular}

Sumber: data Primer yang diolah, 2017

Berdasarkan tabel 3 atas menujukan bahwa seluruh pertanyaan tersebut valid, karena masing-masing memiliki nilai $r$ hitung lebih dari 0,30 ( $\mathrm{r}$ hitung $>\mathrm{r}$ standar).

Pengujian selanjutnya adalah uji validitas untuk variabel Kepatuhan Wajib Pajak. Dimana pengujian tersebut memiliki jumlah pernyataan sebanyak 5 butir. Adapun hasil pengujian validitas untuk variabel Kepatuhan Wajib Pajak dapat dilihat pada tabel 4.

Tabel 4

Hasil Uji Validitas Kepatuhan Wajib Pajak

\begin{tabular}{|c|c|c|c|}
\hline Pernyataan & R hitung & R standar & Keterangan \\
\hline P11 & 0,670 & 0,30 & Valid \\
\hline P12 & 0,775 & 0,30 & Valid \\
\hline P13 & 0,658 & 0,30 & Vadil \\
\hline P14 & 0,814 & 0,30 & Valid \\
\hline P15 & 0,744 & 0,30 & Valid \\
\hline
\end{tabular}

Sumber: data Primer yang diolah, 2017 
Berdasarkan tabel 4.24 atas menujukan bahwa seluruh pertanyaan tersebut valid, karena masing-masing memiliki nilai $r$ hitung lebih dari 0,30 ( $r$ hitung $>$ r standar).

\section{Uji Reliabilitas}

Tabel 5

Hasil Uji Reliabilitas NPWP

Reliability Statistics

\begin{tabular}{c|c} 
Cronbach's Alpha & N of Items \\
\hline, 656 & 5 \\
\hline
\end{tabular}

Sumber: data Primer yang diolah, 2017

Berdasrkan tabel 5 dalam uji reliabilitas diketahui bahwa nilai Alpha Cronbach > 0,60 yakni $(0,656>0,60)$ maka, kuesioner tersebut dinamakan reliabel. Selanjutnya uji reliabilitas untuk variabel Sanski Perpajakan dapat dilihat pada tabel 6.

Tabel 6

Hasil Uji Reliabilitas Sanksi Perpajakan Reliability Statistics

\begin{tabular}{c|c} 
Cronbach's Alpha & N of Items \\
\hline, 670 & 5 \\
\hline
\end{tabular}

Sumber: data Primer yang diolah, 2017

Berdasarkan tabel 6 dalam uji reliabilitas diketahui bahwa nilai Alpha Cronbach >0,06 yakni $(0,670>0,06)$ maka, kuesioner tersebut dinamakan reliable. Selanjutnya uji reliabilitas untuk variebel Kepatuhan Wajib Pajak silihat pada tabel 7.

Tabel 7

Hasil Uji Reliabilitas Kepatuhan Wajib Pajak Reliability Statistics

\begin{tabular}{c|c} 
Cronbach's Alpha & N of Items \\
\hline, 683 & 5 \\
\hline
\end{tabular}

Sumber: data Primer yang diolah, 2017

Berdasarkan tabel 7 dalam uji reliabilitas diketahui bahwa nilai Alpha Cronbach $>0,60$ yakni $(0,783>0,60)$ maka, kuesioner tersebut dinamakan reliabel. 
Uji Regresi Linier Sederhana

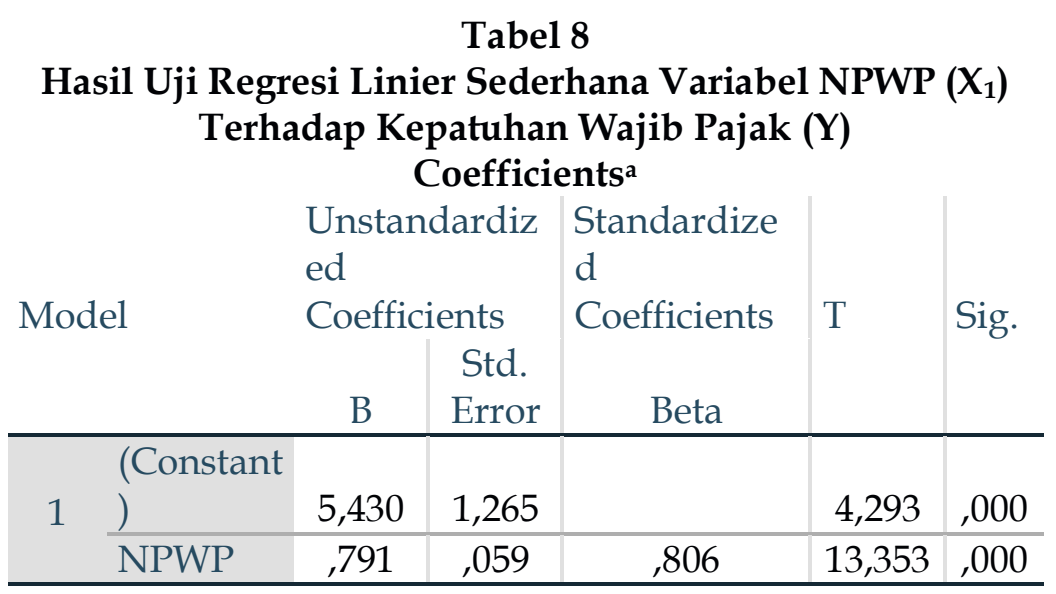

a. Dependent Variable: kepatuhan Wajib Pajak

Sumber: data Primer yang diolah, 2017

Berdasarkan tabel 8 diatas diperoleh konstanta untuk persamaan regresi dengan nilai a sebesar 5,430 dan b sebesar 0,791. Jadi persamaan regresi untuk NPWP terhadap Kepatuhan Wajib Pajak adalah :

$Y=5,430+0,791 X_{1}$

Interprestasi persamaan tersebut yaitu :

Y : Kepatuhan Wajib Pajak

$\mathrm{X}_{1} \quad$ : NPWP

Dari model regresi sederhana tersebut dapat dijelaskan sebagai berikut :

a. Nilai konstanta ( $\alpha$ ) adalah menyatakan bahwa jika tidak ada NPWP $\left(X_{1}\right)$ maka tingkat Kepatuhan Wajib Pajak 5,430.

b. Koefisien regresi 0,791 menunjukan bahwa setiap pertambahan sebesar satu satuan, Kepatuhan Wajib Pajak akan bertambah sebesar 0,791.

Tabel 9

Hasil Uji Regresi Linier Sederhana Variabel Sanksi

Perpajakan $\left(\mathrm{X}_{2}\right)$ Terhadap Kepatuhan Wajib Pajak (Y)

Coefficients ${ }^{a}$

\begin{tabular}{|c|c|c|c|c|c|}
\hline \multirow{2}{*}{ Model } & \multicolumn{2}{|c|}{$\begin{array}{l}\text { Unstandardize } \\
\text { d Coefficients }\end{array}$} & \multirow{2}{*}{$\begin{array}{l}\text { Standardize } \\
\mathrm{d} \\
\text { Coefficients } \\
\quad \text { Beta }\end{array}$} & \multirow{2}{*}{$\mathrm{T}$} & \multirow{2}{*}{ Sig. } \\
\hline & B & $\begin{array}{l}\text { Std. } \\
\text { Error }\end{array}$ & & & \\
\hline (Constant) & 12,925 & 1,571 & & 8,230 & ,000 \\
\hline
\end{tabular}




\begin{tabular}{ll|l|l|l|l}
\hline $\begin{array}{l}\text { Sanksi } \\
\text { Perpajakan }\end{array}$ &, 456 &, 076 &, 520 & 5,971 &, 000 \\
\hline
\end{tabular}

a. Dependent Variable: kepatuhanwajibpajak

Sumber: data Primer yang diolah, 2017

Berdasarkan tabel 9 atas diperoleh konstanta untuk persamaan regresi dengan nilai a sebesar 12,925 dan $b$ sebesar 0,456 . Jadi persamaan regresi untuk Sanksi Perpajakan terhadap Kepatuhan Wajib Pajak adalah

$\mathrm{Y}=12,925+0,456 \mathrm{X}_{2}$

Interprestasi persamaan tersebut yaitu :

Y $\quad$ : Kepatuahn Wajib Pajak

$\mathrm{X}_{2} \quad$ : Sanksi Perpajakan

Dari modal regresi sederhana tersebut dapat dijelaskan sebagai berikut :

1. Nilai konstanta (a) adalah menyatakan bahwa jika tidak ada Sanksi Perpajakan, maka tingkat Kepatuhan Wajib Pajak sebesar 12, 925.

2. Koefisien regresi 0,456 menunjukan bahwa setiap pertambahan sebesar satu satuan, maka Kepatuhan Wajib Pajak akan bertambah sebesar 0, 456.

Uji Regresi Linier Berganda

Tabel 10

Hasil Uji Regresi Linier Berganda Variabel NPWP $\left(X_{1}\right)$ Sanksi Perpajakan $\left(X_{2}\right)$ Terhadap Kepatuhan Wajib Pajak

(Y)

Coefficients $^{\mathrm{a}}$

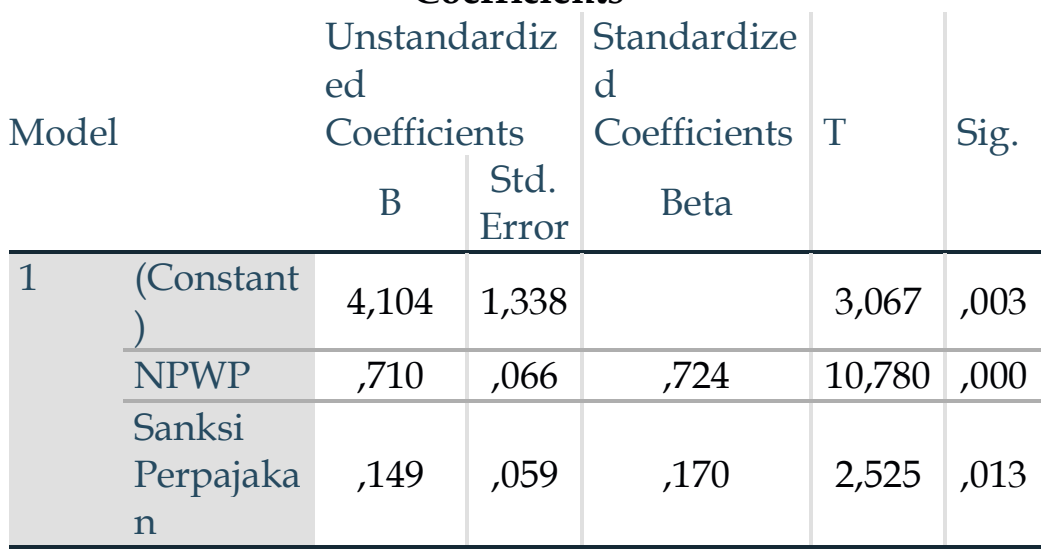

a. Dependent Variable: kepatuhanwajibpajak

Sumber: data Primer yang diolah, 2017 
Berdasarkan hasbil tabel 10 diatas, diperoleh konstanta untuk persamaan regresi dengan nilai a sebesar 4,104, $b_{1}$ 0,710, $b_{2}$ 0,149.

Jika persamaan regresi berganda untuk NPWP dan Sanksi Perpajakan terhadap Kepatuahn Wajib Pajak adalah :

$\mathrm{Y}=4,104+0,710 \mathrm{X}_{1}+0,149 \mathrm{X}_{2}+\mathrm{e}$

Interprestasi persamaan tersebut yaitu :

Y $\quad$ : Kepatuhan Wajib Pajak

$\mathrm{X}_{1} \quad$ : NPWP

$\mathrm{X}_{2} \quad$ : Sanksi Perpajakan

e : eror

Dari modal regresi berganda tersebut dapat dijelaskan sebagai berikut :

a. Nilai konstanta menyatakan bahwa jika tidak ada NPWP dan Sanksi Perpajakan turun 0,710.

b. Koefisien regresi 0,710 menunjukan bahwa setiap penambahan sebesar satu-satuan, NPWP akan meningkat sebesar 0,710.

c. Koefisien regresi 0,149 menunjukan bahwa setiap penambahan sebesar satu-satuan, Sansi Perpajakan akan meningkat sebesar 0,149.

\section{Uji Korelasi Sederhana}

Tabel 11

Hasil Uji Korelasi Sederhana Variabel NPWP $\left(X_{1}\right)$ Terhadap Kepatuahn Wajib Pajak (Y)

Correlations

\begin{tabular}{llc|c} 
& NPWP & $\begin{array}{c}\text { Kepatuhan } \\
\text { Wajib Pajak }\end{array}$ \\
\hline \multirow{3}{*}{ NPWP } & $\begin{array}{l}\text { Pearson } \\
\text { Correlation }\end{array}$ & 1 &, $806^{* *}$ \\
\cline { 2 - 4 } & Sig. (2-tailed) & &, 000 \\
\cline { 2 - 4 } & $\mathrm{N}$ & 98 & 98 \\
\hline \multirow{3}{*}{$\begin{array}{l}\text { Kepatuhan } \\
\text { Wajib Pajak }\end{array}$} & $\begin{array}{l}\text { Pearson } \\
\text { Correlation }\end{array}$ &, $806^{* *}$ & 1 \\
\cline { 2 - 4 } & Sig. (2-tailed) &, 000 & \\
\cline { 2 - 4 } & $\mathrm{N}$ & 98 & 98 \\
\hline
\end{tabular}

**. Correlation is significant at the 0.01 level (2-tailed).

(Sumber: data Primer yang diolah, 2017) 
Berdasarkan tabel 11 diproleh nilai koefisien korelasi sebesar 0,806, karena menurut interprestasi koefisien kriteria 0,80 sampai dengan 1,0000 maka dapat disimpulkan bahwa terdapat hubungan yang sangat kuat antara $X_{1}(\mathrm{NPWP})$ terhadap Y (Kepatuhan Wajib Pajak)

Tabel 12

Hasil Uji Korelasi Sederhana Variabel Sanksi Perpajakan $\left(\mathrm{X}_{2}\right)$ Terhadap Kepatuahn Wajib Pajak (Y) Correlations

\begin{tabular}{|c|c|c|c|}
\hline & & $\begin{array}{c}\text { Sanksi } \\
\text { Perpajaka } \\
\text { n }\end{array}$ & $\begin{array}{l}\text { Kepatuhan } \\
\text { Wajib Pajak }\end{array}$ \\
\hline \multirow[t]{3}{*}{$\begin{array}{l}\text { Sanksi } \\
\text { perpajakan }\end{array}$} & $\begin{array}{l}\text { Pearson } \\
\text { Correlation }\end{array}$ & 1 &, $520^{* x}$ \\
\hline & Sig. (2-tailed) & & ,000 \\
\hline & $\mathrm{N}$ & 98 & 98 \\
\hline \multirow[t]{3}{*}{$\begin{array}{l}\text { Kepatuhan } \\
\text { Wajib Pajak }\end{array}$} & $\begin{array}{l}\text { Pearson } \\
\text { Correlation }\end{array}$ &, $520^{* *}$ & 1 \\
\hline & Sig. (2-tailed) & ,000 & \\
\hline & $\mathrm{N}$ & 98 & 98 \\
\hline
\end{tabular}

**. Correlation is significant at the 0.01 level (2-tailed).

(Sumber: data Primer yang diolah, 2017)

Bersadarkan tabel 12 diatas diproleh nilai koefisien korelasi sebesar 0,520, karena menurut interprestasi koefisien kriteria dari 0,40 sampai dengan 0,599 maka dapat disimpulkan bahwa terdapat hubungan yang sedang antara $\mathrm{X}_{2}$ (Sanksi Perpajakan) terhadap (Y) Kepatuahan Wajib Pajak.

\section{Uji Korelasi Berganda}

Tabel 13

Hasil Uji Korelasi Berganda Variabel NPWP $\left(X_{1}\right)$ dan Sanksi Perpajakan $\left(X_{2}\right)$ Terhadap Kepatuahn Wajib

Pajak (Y) Model Summary

\begin{tabular}{lr|r|r|r} 
Model & $\mathrm{R}$ & $\mathrm{R}$ & $\begin{array}{c}\text { Adjusted } \\
\text { Square }\end{array}$ & $\begin{array}{c}\text { Std. Error of the } \\
\text { R Square }\end{array}$ \\
\hline 1 &, $820^{\mathrm{a}}$ &, 672 &, 665 & 1,065 \\
\hline
\end{tabular}

a. Predictors: (Constant), Sanksi Perpajakan, NPWP

Sumber: data Primer yang diolah, 2017 
Berdasrkan tabel 13 diatas diperoleh nilai koefisien korlasi sebesar 0,820. Karena menurut interprestasi koefisien kriteria dari 0,80 sampai 1,0000 maka dapat disimpulkan bahwa terdapat hubungan yang sangat kuat antara $\mathrm{X}_{1}$ (NPWP) dan $\mathrm{X}_{2}$ (Sanksi Perpajakan) secara simultan terhadap variabel Y (Kepatuhan Wajib Pajak).

\section{Kesimpulan}

Penelitian ini bertujuan untuk menganalisis pengaruh NPWP dan Sanksi Perpajakan Terhadap Kepatuhan Wajib Pajak pada Universitas Islam Syekh-Yusuf Tngerang. Responden dalam penelitian ini berjumlah 98 orang wajib pajak yang barada di Civitas Akademika Universitas Islam Syekh-Yusuf Tangerang.

Berdasarkan hasil analisis terhadap data yang dikumpulkan, maka dapat diambil kesimpulan bahwa :

1. Terdapat hubungan yang sangat kuat antara NPWP terhadap kepatuhan wajib pajak dengan nilai korelasi 0,806. Kontribusi NPWP terhadap kepatuhan wajib pajak sebesar 65,0\% sisanya 35,0\% dipengaruhi oleh faktor lain yang belum diteli dikarenakan keterbatasan waktu dan biaya. Hasil uji $\mathrm{t}$ variabel $\mathrm{X}_{1}$ menyatakan bahwa NPWP berpengaruh positif dan signifikan terhadap kepatuhan wajib pajak, hal ini dapat dilihat dari nilai signifikansi yaitu sebesar 0,000 dan t hitung $>$ t tabel $(13,353>1,984)$, maka Ho1 ditolak dan Ha1 diterima.

2. Terdapat hubungan yang sedang antara Sanksi Perpajakan terhadap kepatuhan wajib pajak dengan nilai korelasi 0,520. Kontribusi Sanksi Perpajakan terhadap kepatuhan wajib pajak sebesar 27,1\% sisanya $72,9 \%$ dipengaruhi oleh faktor lain yang belum diteli dikarenakan keterbatasan waktu dan biaya. Hasil uji $\mathrm{t}$ variabel $\mathrm{X}_{2}$ menyatakan bahwa sanksi perpajakan berpengaruh positif dan signifikan terhadap kepatuhan wajib pajak, hal ini dapat dilihat dari nilai signifikansi yaitu sebesar 0,000 dan $\mathrm{t}$ hitung $>\mathrm{t}$ tabel $(5,971>1,984)$, maka Ho2 ditolak dan $\mathrm{Ha} 2$ diterima. 
3. Terdapat hubungan yang sangat kuat antara NPWP dan sanksi perpajakan secara simultan terhadap kepatuhan wajib pajak dengan nilai korelasi 0,820. Kontribusi NPWP dan Sanksi Perpajakan terhadap kepatuhan wajib pajak sebesar $67,2 \%$ sisanya 32,8\% dipengaruhi oleh faktor lain yang belum diteli dikarenakan keterbatasan waktu dan biaya. Hasil uji F menyatakan bahwa NPWP dan sanksi perpajakan berpengaruh positif dan signifikan terhadap kepatuhan wajib pajak, hal ini dapat dilihat dari nilai signifikansi yaitu sebesar 0,000 dan F hitung > F tabel $(97,331>3,09)$, maka Ho3 ditolak dan Ha3 diterima.

\section{Implikasi}

Ada pun beberapa saran yang dapat disampaikan berdasarkan kesimpulan dari hasil penelitian ini adalah sebagai berikut :

1. Diharapkan dapat menambahkan variabel independen lainnya, untuk mengetahui variabel-variabel lain yang dapat mempengaruhi dan memperkuat atau memperlemah variabel dependen.

2. Penelitian selanjutnya diharapkan menggunakan sampel penelitian lebih besar.

3. Penelitian selanjutnya diharapkan agar meneliti lanjut mengenai faktorfaktor lain yang memiliki pengaruh terhadap kepatuhan wajib pajak dan agar memperluas ruang lingkup penelitiannya.

\section{Keterbatasan Penelitian}

Penelitian ini msih memiliki keterbatasan sehingga masih perlu untuk disempurnakan. Adapun keterbatasan penelitian sebagai berikut :

1. Sampel dalam penelitian ini terbatas atau kurang meluas hanya di wilayah Civitas akademika Universitas Islam Syekh-Yusuf Tangerang.

2. Penelitian ini hanya berfokus pada NPWP dan sanksi perpajakan terhadap kepatuhan wajib pajak. 


\section{DAFTAR PUSTAKA}

\section{AL-QUR'AN}

Ghozali, I. 2011. Aplikasi Analisis Multivariate dengan Program IMB SPSS 22. Edisi Ketiga. Semarang : Badan Penerbit Universitas Diponegoro.

Masruroh, S. 2013. Pengaruh Kemanfaatan NPWP, Pemahaman Wajib Pajak, Kualitas Pelayanan, Sanksi Perpajakan Terhadap Kepatuhan WPOP Di Kabupaten Tegal. Fakultas Ekonomi Dan Bisnis Universitas Diponegoro, Semarang. Vol. 2 No. 4, Hal 1-15.

Muljoko, Djoko. 2010. Panduan Brevet Pajak Penghasilan. Yogyakarta : Andi Offset.

Priyatno, Duwi. 2013. Mandiri Belajar Analisis Data dengan SPSS. Yogyakarta : Media Kom.

Purwono, H. 2010. Dasar-Dasar Perpajakan dan Akuntansi Pajak. Jakarta : Penerbit Erlangga.

Pujiwidodo, D. 2016. Persepsi Sanksi Perpajakan Terhadap Kepatuhan Wajib Pajak Orang Pribadi. Akademi Manajemen Keuangan BSI Jakarta. Jurnal Online Insan Akuntan Vol. 1 No.1 Juni 2016, Hal. 92-116.

Rahayu SK dan Suhayati, E. 2010. Perpajakan, Teori dan Teknis Perhitungan. Yogyakarta : Graha Ilmu. 139

Resmi, Siti. 2016. Perpajakan Teori dan Kasus. Edisi Kedelapan. Jakarta : Selemba Empat.

Setiawati, Lilis dan Anastasia Diana, 2014. Perpajakan Teori dan Peraturan Terkini. Yogyakarta : Andi Offset.

Sugiyono, 2010. Metode Penelitian Bisnis. Bandung: Alfabeta.

Sutrisno, B. 2016. Pengaruh Kewajiban Kepemilikan NPWP, Pemeriksaan Pajak, Penagihan Pajak, Surat Paksa Pajak dan Kesadaran Wajib Pajak Terhadap Penerimaan Pajak Pada Kantor Pelayanaan Pajak Pratama di Kota Semarang. Fakultas Ekonomi dan Jurusan Akuntansi Universitas Pandanaran, Semarang. Jurnal EMBA Vol. 2 No.2 Maret 2016, Hal.1-20. 
Tiraada TAM, 2013. Kesadaran Perpajakan, Sanksi Pajak, Sikap Fiskus Terhadap Kepatuhan WPOP Di Kabupaten Minahasa Selatan. Fakultas Ekonomi Dan Bisnis Universitas Sam Ratulagi, Manado. Jurnal EMBA Vol.1 No. 3 Septemeber 2013, Hal.999-1008.

Waluyo, 2014. Perpajakan Indonesia. Edisi Kesebelas. Jakarta : Selemba Empat.

Winerungan, O.L. 2013. Sosialisasi Perpajakan, Pelayanan Fiskus dan Sanksi Perpajakan Terhadap Kepatuhan WPOP Di KPP Manado dan KPP Bitung. Fakultas Ekonomi Dan Bisnis Universitas Sam Ratulangi, Manado. Jurnal EMBA Vol. 1 No. 3 September 2013, Hal. 960-970. 